Perceptual and Motor Skills, 1984, 58, 223-226. (C) Perceptual and Motor Skills 1984

\title{
THE ZEIGARNIK PHENOMENON REVISITED: IMPLICATIONS FOR ENHANCEMENT OF MORALE ${ }^{1}$
}

\author{
BENJAMIN B. WEYBREW
}

University of New Haven

\begin{abstract}
Summary.-Zeigarnik's notion of need tension following task interruption was reexamined by comparing the time estimates of task-interrupted and taskcompleted groups ( $n=15$ each). Overestimation characterized the former and underestimation the latter group. Tasks with clear endpoints are thought to be associated with high morale.
\end{abstract}

The Lewinian concept of psychological tension as demonstrated by Bluma Zeigarnik's finding more than five decades ago that task interruption tended to enhance recall of its content suggests the possibility that retrospective perception of a given time span following task interruption may be a useful measure of what she called at the time "sustained need tension" (Zeigarnik, 1927). This proposition emerges from selected findings in the literature on time perception. For example, Gulliksen (1927) published data suggesting that passage of time during void intervals (analogous to intervals following task interruption) tended to be overestimated, while filled, active time periods tended to be underestimated. Further, the magnitude of negative time estimates, i.e., underestimation, appeared to increase as a monotonic function of the intensity of induced muscular tension (Weybrew, 1963).

The present study was designed to examine the effects upon the size and direction of time estimates resulting from the interruption of two kinds of tasks, one a presumably meaningful arithmetical exercise and the other a repetitive letter-cancellation task. This dimension of task meaningfulness was introduced as a second experimental variable as the result of some findings from three studies on time perception and the Zeigarnik effect. One study reported that subjects with "strong egos" recall more completed tasks while those with "weak egos" recall more incompleted tasks (Alper, 1946). Two additional studies showed that negative accuracy was associated with meaningful task activity and overestimation of time intervals with less meaningful tasks (Rosensweig \& Koht, 1933; Filer \& Meals, 1949).

In a sense this study is essentially heuristic since the underlying assumption was not directly tested, the assumption being that environmental circumstances which produce underestimates tend, as Lewin (1942) had suggested, to enhance and sustain group morale, whereas conditions resulting in overestimates would be expected to be characteristic of groups with inadequate morale. Stated more

${ }^{1}$ Reprints may be requested from the author at the following address: 174 Shore Road, Waterford, CT 06385. 
succinctly, this study focused only on the effects of task interruption on the accuracy of time estimates, leaving the more ultimate hypothesis that underestimates are characteristic of, and, quite possibly, basic to favorable group morale to be examined by further research.

\section{Subjects \\ METHOD}

Two groups of 15 each were randomly selected from a university introductory psychology class. All subjects were male volunteers; their ages ranged from 17 to $24 \mathrm{yr}$. with a mean of 20.2 yr. They were thoroughly briefed on the general nature of the study, namely, that it involved their estimates of the duration of specific time intervals. Moreover, they were assured that they would not experience any significant discomfort as a result of the procedures and that they would be free to withdraw from the experiment at any time.

\section{Procedure}

A repeated-measurements, control group design was used, the experimental group being the task-interrupted group and the control group the task-completed group. The data were collected in a quiet classroom with no clocks visible. The subjects were asked not to look at their timepieces during data collection and were closely monitored to assure their compliance with this instruction.

Phase I required each member of the task-interrupted group to solve the 12 addition problems (4 3-digit random numbers in each) presented on a 3- $\times 8$-in. worksheet. When completed, the subjects were asked to estimate the time in minutes and seconds taken to complete the sums. For convenience, this estimate was called Chronometric Interval number one $\left(\mathrm{CI}_{1}\right)$. After a 3 -min. break, phase II was begun. The subjects were asked to sum another set of addition problems, but this time there were 25 different problems spread out on an $8-\times 11$-in. page. After beginning to solve the second set of addition problems, these subjects were interrupted at the point at which the time period $\mathrm{CI}_{1}$ had elapsed. At that time the experimenter stated: "I guess this will be enough addition practice for today; however, would you again please estimate in minutes and seconds how long you think you have been working on this second batch of addition problems?" This time estimate was labelled $\mathrm{Cl}_{2}$ The accuracy of time estimates for $\mathrm{CI}_{1}$ and $\mathrm{CI}_{2}$ were calculated as follows:

$$
A \mathrm{AE}_{1}=\left[\left(\mathrm{CI}_{1}-\mathrm{CI}_{\mathrm{r}}\right) / \mathrm{CI}_{\mathrm{t}}\right] \times 100,
$$

where $A T E_{1}=$ Accuracy of time estimate in percentage for $\mathrm{CI}_{1}$ as defined above; $\mathrm{CI}_{\mathbf{6}}=$ true stopwatch-timed chronometric interval. $\mathrm{ATE}_{2}$, involving $\mathrm{CI}_{2}$, was calculated in precisely the same manner. Obviously the ATE scores could be either positive or negative. After a 30-min. rest period, the same procedure was carried out with the same experimental or interrupted group's being administered the letter-cancellation task in the same sequence. $\mathrm{Cl}_{1}$ data were obtained by asking the subjects to cancel all of the letter "i's" and "s's" in 9 lines of average difficulty, expository writing again printed on a 3 - $\times 8$-in. worksheet. $\mathrm{Cl}_{15}$ were obtained as before when the cancellations were completed. After 3 min., cancellations were performed on 20 different lines of similar script on an $8-X$ 11 -in. sheet. $\mathrm{CI}_{2 \mathrm{~S}}$ were given by the subjects after again being interrupted at $\mathrm{CI}_{1}$. ATEs were calculated in the same manner as they were with the arithmetic exercise.

The data collection for the control or non-interrupted group for both tasks consisted of calculating ATEs for the $\mathrm{Cl}_{1}$ s obtained exactly as before in Phase I for the experimental 
group. However, this time Phase II was a repetition of Phase I, that is, subjects were allowed to complete (without interruption) a second set of 12 addition problems again on a 3- $\times$ 8-in. sheet. Subjects then reported their $\mathrm{CI}_{2}$ from which their $A \mathrm{TE}_{2}$ scores were derived. Again, after a 30-min. break, the same procedure was completed for the letter-cancellation task.

Since the accuracy of time estimates were in percentage form, sharp and somewhat unpredictable skews in their distributions were anticipated. As a result, non-parametric significance tests were used.

\section{RESULTS}

The median and range $\mathrm{CI}_{t}$ (actual time taken to complete the trials) for the addition task was $2 \mathrm{~min}$. $40 \mathrm{sec}$. and $85 \mathrm{sec}$., respectively; for the cancellation task the median was $2 \mathrm{~min}$. $25 \mathrm{sec}$., with a range of $80 \mathrm{sec}$. Calculated as described in the procedure section, the estimates for both tasks for Phase I (task completion) were subtracted algebraically from those for Phase II (task interrupted for the experimental group and the repeated task-completed trial for the control group). The medians and ranges of these distributions of ATE difference scores for each group and both tasks are presented in Table 1.

TABLE 1

MEdians and Ranges of Distributions of Differences BeTween ACCuRACY OF TIME ESTTMATES OF TASK-INTERRUPTED AND TASK-COMPLETED GROUPS

\begin{tabular}{|c|c|c|c|c|c|}
\hline Groups & $N$ & & $\begin{array}{l}\text { \% Addition } \\
\text { Problems }\end{array}$ & $\begin{array}{c}\% \text { Letter } \\
\text { Cancellation }\end{array}$ & $p^{*}$ \\
\hline Task-interrupted & 15 & $\begin{array}{l}M d n \\
\text { Range }\end{array}$ & $\begin{array}{c}+20 \\
52(-2 \text { to }+50)\end{array}$ & $\begin{array}{c}+11.8 \\
33(-3 \text { to }+30)\end{array}$ & .06 \\
\hline $\begin{array}{l}\text { Task-completed } \\
p^{*}\end{array}$ & 15 & $\begin{array}{l}M d n \\
\text { Range }\end{array}$ & $\begin{array}{c}-2 \\
43(-28 \text { to }+15) \\
.06\end{array}$ & $\begin{array}{c}-13.8 \\
40(-38 \text { to }+2) \\
.06\end{array}$ & .15 \\
\hline
\end{tabular}

The fact that the differences berween the median accuracy of time estimates for the task-interrupted group as compared to the task-completed group for borh kinds of tasks approach acceptable significance levels (.06, two-tailed tests) suggests that ATE scores tend to be positive for interrupted and negative for completed task activity. Moreover, the size of the overestimates following interruption appear to be greater for the presumably more challenging addition problems than for the repetitious cancellation task. While suggestive that the underestimates for the cancellation trials are considerably larger, the betweentask differences in -ATEs did not reach acceptable statistical significance (.15).

As hypothesized and theoretically consistent with Zeigarnik's notion of a sustained "tension state" following task interruption, time overestimation appears to be typical, at least when addition and letter cancellation constitute the 
interrupted tasks. Further, while statistically less convincing, the findings in this study nonetheless suggest that underestimation of time intervals tends to be associated with completed tasks. If as Lewin (1942) seemed to imply underestimation of passage of time tends to be associated with optimal morale, one somewhat extrapolative implication of this study becomes: to the extent that people in general, and, in particular those engaged in repetitious activities dayin-and-day-out, participare in planned activities with clearly perceptible end points, to that extent will the passage of time be underestimated (-ATEs), and, hypothetically at least, will favorable group morale be artained and sustained.

Finally, assuming that the validity of the relationships between time underestimation and perceived end phases of task activity and the latter and elevated morale can be more firmly established, the implications for work flow and job design strategies in industrial and other organizational settings would be obvious.

\section{REFERENCES}

ALPER, T. G. Memory for completed and incompleted tasks as a function of personality. Journal of Abnormal and Social Psychology, 1946, 41, 403-420.

FILER, R. J., \& MEALS, D. W. The effect of motivating conditions on the estimation of time. Journal of Experimental Psycbology, 1949, 39, 327-331.

GulliksEN, $H$. The influence of occupation upon the perception of time. Journal of Experimental Psychology, 1927, 10, 52-59.

LEwiN, K. Time perspective and morale. In C. Watson (Ed.), Civilian morale. Boston: Houghton Mifflin, 1942. Pp. 48-70.

RoSENZWEIG, S., \& KOHT, A. The experience of duration as affected by need tension. Journal of Experimental Psychology, 1933, 16, 745-774.

Weybrew, B. Accuracy of time estimation and muscular tension. Perceptual and Motor Skills, 1963, 17, 118.

WILCOXON, F. Individual comparisons by ranking methods. Biometrika, 1945, 1, 80-83.

ZEIGARNIK, B. Über das Behalten von erledigten und unerledigten Handlungen. Psy. chologische Forscbung, 1927, 9, 1-85.

Accepted January 9, 1984. 